\title{
Governance, accountability and the datafication of early years education in England
}

\section{Guy Roberts-Holmes and Alice Bradbury}

\section{UCL Institute of Education, University College London.}

\begin{abstract}
In this paper we attempt to make visible the flow and circulation of data through analysing the datafication of the early years education sector in England (children aged 2-5). The concept of datafication is used to understand the processes and impacts of burgeoning data-based governance and accountability regimes. This analysis builds upon early childhood researchers who were influenced by Foucault and others, who have noted the ways in which the surveillance and performative culture of accountability both affirms, legitimates and seduces the early years through discourses of 'quality' whilst increasingly regulating and governing the early years. Using data from three research sites (a Children's Centre, a Primary school and a combined Nursery School and Children's Centre) as well as an interview with a Local Authority Early Years Advisor, we examine how comparative data-based accountability increasingly governed early years teachers' professionalism and pedagogies. We argue that the planned tracking of children's performance from Baseline testing (DfE, 2014) at four years old to eleven years old may further govern and constrain early years professionalism as young children are reconfigured as 'miniature centres of calculation'
\end{abstract}

Keywords, Data, early years, accountability, governance.

\section{Introduction}

Education policy in England under the Conservative-Liberal Democrat Coalition Government (2010-2015) was guided, particularly during the time when Michael Gove was the Secretary of State for Education, by an aim to produce a 'post-bureaucratic school system' (Gove, 2009). This desire to reduce 'red tape' and 'tick boxes' (Gove, 2009) and 'allow teachers to teach', was accompanied by extensive accountability reform in the Early Years Foundation Stage (DfE, 2011) which caters for children from birth to five years in a wide range of private and state settings. This reform included the reduction of the statutory assessment at age five (DfE, 2013a) from 117 to 17 points, an increased focused on Mathematics and English for 3-5 year olds and higher expectations for the benchmark measure of success in the EYFS Profile (EYFSP), known as reaching Good Levels of Development. As part of this accountability reform the EYFS Profile (EYFSP) will become optional from 2016 and be replaced with commercially produced Reception Baseline Assessments for four-year-olds to be phased in from September 2015 (DfE, 2014). These Baseline Assessments will produce a single numerical data score for the purpose of tracking children's progress through primary school to age 11 . Hence despite the aim of reducing bureaucracy, one outcome of these accountability reforms has been the increased production, analysis and comparison of what Selwyn et al (2015b) characterize as 'compliance data', as opposed to 'useful data' in the early years. It is this ‘datafication' which is our focus here.

\section{Governance, Accountability and datafication within the Early Years}


Foucault (1977) argued that governance involves the use of a range of technologies to exercise power over the actions of individuals, who both willingly comply through processes of self-governance, and resist, 'He who is subjected to a field of visibility, and who knows it, assumes responsibility for the constraints of power; he makes them play spontaneously upon himself; he inscribes in himself the power relation in which he simultaneously plays both roles; he becomes the principle of his own subjection' (Foucault, 1977 202-203). Although writing in a different era in terms of the proliferation of digital data, many of Foucault's concerns in relation to governance and self-governance can be applied to the modern education system (Selwyn, 2015a). Data-based accountability governs education (Ozga, 2011), in this sense, by operating as a technology that is an 'indefinite discipline, an interegation without end' (Foucault, 1977, 227). Through making schools visible and knowable, networks and databases have become dominant techniques of governing (Lawn, 2009; Lingard, 2013; Ozga, 2009, 2011, Williamson, 2014b) so that comparative data 'are the technologies of governing' and key to the 'governance turn' (Fenwick et al 2014, 6). Williamson (2014b) and Fenwick et al (2014) argue that such digital data has become 'interwoven' with the governance of education and represents an artefact of 'digital governance'. These processes of governance through data, we argue here, increasingly apply to the early years sector.

There is a wealth of literature within studies of early childhood internationally which has been concerned with the increasingly regulation of the education and care of young children, and particularly the power of discourses of accountability and 'quality' (Dahlberg, et al, 2007; Hatch \& Grieshaber, 2002; Jones et al, 2014; Osgood 2010, 2012; Moss, 2014; Urban, 2015). Here we update this scholarship in relation to the context of England, by focusing specifically on the use of data to govern early years practices. This builds on work such as Osgood (2010), who noted how early childhood workers become self-governing professionals under the gaze of simplified governing data, and our own research into assessment and the collection of data in the sector (Bradbury, 2013; Roberts-Holmes, 2015). This analysis is particularly important at the present moment, as from September 2015 the Baseline Assessments carried out in the Reception year (age four/five) (DfE, 2014) will produce simplified accountability data in the form of a single number. Thus the primary school performance culture will be officially extended downwards to the early years, to ensure what Ball et al have called 'the delivery of improved systematic and institutional performances - all of which are part of a broader neo-liberal 'audit culture' embedded in the public sector' (Ball et al, 2012b, 514). Within the 'the hegemony of neo-liberal economy and gouvernementalité' (Urban, 2015, 5), early years becomes the starting line for measurements of school 'quality', set within the broader 'global economic race'; young children are constructed as fertile ground for future education and employment so that 'early years education is reduced to a commodity to increase an individual's 'human capital' and usefulness (employability) in a narrowly-defined neo-liberal economy — homo economicus' (Urban, 2015). Similarly, we argue that calculable market place economics has the tendency to draw the wider social purposes of early years education into an economic and industrial policy (Ball, 2013) so that early years ‘quality' data-accountability measurements need to be understood as 'deeply political and driven by economic imperatives' (Osgood and Giugni, 2015, 3). In this way our research builds on Moss (2014) who argues that there is an ever stronger governing of the early years teacher and child such that 'complexity and messiness, diversity and context, the social and the cultural must and can be controlled, reduced and tamed, spurred on by the belief that there must be one right answer for every question, one calculable rate of return on any investment' (Moss, 2014, 66). Within all this, data based accountability replaces the flux and uncertainty of 
'liquid modernity' (Bauman and Lyon, 2014), with the solidity of 'facts' and numbers that purport to demonstrate 'impact' and therefore worth.

Our particular concern with data and 'datafication' in education resonates with a broader interest in this area from within education research and in 'digital sociology' (Selwyn, 2015b). This interest arises from the expansion of data in society more generally, and particularly with the shift in terms of "volume, velocity and variety' of data (Laney, 2001 cited in Selwyn, 2015b) in recent years. We aim to consider the concerns raised in relation to compulsory and higher education data processes in the specific context of the early years sector in England. This discussion is framed by the notion of 'the politics of data' (Selwyn, 2015a), the idea that data are not neutral constructions used in neutral ways, but powerfully influenced by particular concepts of what can be measured and analysed.

\section{Methods}

Two researchers were engaged in a 12 month qualitative research project that focused upon the three main types of early years state English provision, a Children's Centre; a Nursery and Reception Class in a Primary School; and a combined Nursery School and Children's Centre. We also involved a local authority Early Years advisor, to provide an alternative perspective on school practices. Access to the three different case study sites was identified through opportunistic sampling and existing research relationships from an earlier project (RobertsHolmes, 2014). At each site, interviews with several staff, focus group discussions and some limited observations were conducted. Documentary data including anonymised Excel spreadsheets of assessment data were also collected; these were seen as the 'products' of datafication. Across the three sites, interviews and focus group discussions were held with, Children's Centre Managers; the Nursery school head teacher; two deputy headteachers; two Early Years Foundation Stage (EYFS) leaders and four early years teachers. In addition, we carried out a 90 minute interview with a local authority advisor, unconnected to any of the sites. In all interviews, semi-structured interview schedules which focused on the practices relating to assessment, the collection and processing of data, reporting of data to the local authority and the role of Ofsted were used. The interviews with Primary School and Children's Centre staff lasted between 30 minutes and one hour, totalling seventeen hours of recorded interviews. The interview data were transcribed and systematically organised around codes and placed into thematic categories based on theoretical concepts emerging from the theoretical framework discussed above. After transcription the participants were provided with email copies of the salient points of each interview which prompted further dialogue and correspondence. The email exchanges built upon and developed the themes identified in the earlier interviews and totalled 115 emails across the three sites. The research was conducted within the BERA Ethical Guidelines; the three case study sites and teachers' were given pseudonyms to protect the participants' anonymity.

\section{Westhill Children's Centre}

Westhill Children's Centre was located in a deprived inner London borough where a wide range of activities took place, including nursery classes, drop-in, 'stay and play' sessions, midwifery services and postnatal care. Westhill had two groups of children who regularly attended the centre, the two-year-olds and the nursery class for three to four-year-olds. The two year olds attended for 15 hours a week three mornings a week, taking part in 
a range of activities inside and outside; in the nursery class, some children attended for longer, 'topping up' their allocated hours by parents paying a fee. These 15 hours of education and care are provided free of charge for children whose parents qualified for a range of benefits, including income support (UK Government 2014) from the age of two. The centre was required to provide data on the two and three year olds to the Local Authority every three months and to the Primary schools when the children moved on.

\section{Easthorne Primary School}

We conducted research with Early Years Foundation Stage (EYFS) Nursery class for three- and four-year-olds and the Reception class for four- and five-year-olds at Easthorne, an inner city primary school in another area of London. As well as ongoing assessment, the EYFS teachers had responsibility for providing data for the EYFS Profile, the statutory assessment reported to the local authority and parents at the end of Reception. The EYFS coordinator attended meetings within the Primary school and Local Authority to discuss the data, and the Senior Management Team and LA Early Years Advisors to scrutinise and compare the early years data with other comparable schools.

\section{Hopetown Nursery School and Children's Centre}

Hopetown Nursery School and Children's Centre was located in a socially mixed area of a city in the South West of England. In order to provide the 15 hours free care for disadvantaged two year olds, the Nursery school had recently opened a Children's Centre for this group on a separate site. Data were collected regularly on the children and their families, and this data flowed rapidly between the Nursery school, the Children's Centre, the local primary schools and the Local Authority. To illustrate the sheer volume of digital data traffic, the Nursery Headteacher showed one of us, three comparative data sets that he had received by email during a forty five minute interview.

\section{The Local Authority}

The local authority Early Years advisor was based in a separate borough, in a diverse and deprived area of London. An experienced early years teacher and advisor, his role involved supporting both primary schools and private and voluntary settings within the borough, primarily with assessment and the collection of data. He described his role as 'support and challenge'. We interviewed the Early Years advisor at our university (at his request) using a similar interview schedule, but with a greater focus on the 'statistical journey' of the data collected in early years settings. The advisor also provided additional documentation relating to the local authority's role in collecting data.

\section{Overwhelmed by 'datafication'}

Across the three sites the teachers articulated how they were increasingly subjected to the demands of data production; they were aware of the pitfalls, cynical about the purposes of data, and yet, in an intensified form of the findings of previous research (Bradbury, 2012; Osgood, 2010; 2012), they found their working lives constrained by exhaustive demands for the production and analysis of data. 
'The collection and analysing of data is just too overwhelming. It makes you constantly think of how to improve it and what to do with this group and how to plug this hole and that one. I fill in trackers frequently and I feel a personal pressure to make them progress'. (Reception teacher, Easthorne Primary School).

Rather than challenging or subverting such regulation this teacher self-governed by intensifying her workload to demonstrate constant and uninterrupted progress and development for all children at all times. For the early years teachers in this study, the focus of assessment data was the concept of constant 'progress' through the Early Years Foundation Stage; everyone must be 'tracked' to ensure they are moving forwards. This requires ever more detailed data, to show the incremental progress of the children. The production of data was part of an elaborate performance for Ofsted; inspection has always required this performance (Perryman, 2009) but there was now a need in the case sites to engage in that performance throughout the year, not just when Ofsted arrive. Thus the data production and analysis spreads in terms of time, as well as in its reach. The exponential rise of digital surveillance within early childhood settings has enabled the act of 'seeing' and the surveillance of data to become viral (Lawn, 2013) so that the digital 'gaze' is always 'on' and it 'can see faster and wider than ever before' (Lawn, 2013).

'You have to track children all the time and I have to add everyone's data at the end of each term to the school tracker. Have they performed appropriately and if not why not and what interventions are going to have go in? Nobody's allowed to fall behind. The tracking begins from Nursery in the Prime Areas and right through to year 6. If you are exceeding at the end of Reception you have to show that you are exceeding at the end of KS1 and if not then we are not doing our job'. (Deputy Head teacher, Easthorne Primary School).

This is the disciplinary power of uncertainty, where no one can be content but instead has to be constantly selfreforming, self-improving and showing progress. The constant need to show progress involved the production of ever more complex grids, charts, graphs and tables with acronyms related to a colour-coded, age-based system of points the children can attain, and the security of this attainment in relation to their age, recorded as 'developing', and 'secure'. Such high stakes 'compliance' data was needed for the purposes of regulatory inspection and was contrasted with the more 'useful data' (Selywn, 2015b) in the form of narrative and formative assessments based on teachers' observations. The Hopetown Children's Centre Manager argued that collecting vast amounts of metadata was simply for accountability and not about pedagogy.

'So there's two kinds of data, the metadata and the micro and they get mixed up which suggests people don't understand what they are for. Large scale data is not useful for pedagogy... It's just an accountability tool. The large scale whole school data is the same in every school in the country so why should we measure it when there's nothing we can do about it? It's much better to focus on the detailed qualitative data that focuses upon a child's interests and how to develop and build upon that'. (Hopetown Children's Centre Manager).

The compliance data grids that early years teachers had to constantly produce for children from age two acted as the 'malicious minutae' (Foucault, 1977, 226) of regulatory surveillance and had become a 'relentless and inescapable' (Ozga 2009, 154) feature that make up early years education (Ozga, 2011, 1). For the early years teachers in the study, the relentless filling in, monitoring, and evaluation of 'trackers', assessment sheets and 
profiles both handwritten and on the computer constituted the techniques of governmentality as they struggled with the constant necessity to improve performance.

'Where do you stop with it because there is so much of it! Health data, education data, family support data and well-being data and to be perfectly honest I just can't cope with that much data all the time! So I have put people in place people who can manage that data. (Headteacher, Hopetown Nursery School and Children's Centre).

Similarly to Selwyn's et al's (2015b) interviews with Australian secondary school teachers, this nursery head teacher 'begrudgingly accepted' digital governance 'with indifference rather than cynicism or resistance'. As early years multi-agency working expanded, the headteacher agreed that accountability was a necessary requirement but that at the same time he was overwhelmed and 'burdened with the responsibility to perform' (Ball and Olmedo, 2013, 88) by constantly having to improve performance across an ever increasing range of education and health data streams. However, similarly to Osgood's (2012) findings amongst nursery workers, the headteacher did not specifically challenge the increase in early years regulation and accountability as it was intimately bound up with his professionalism. Ironically, the Nursery teacher promoted to manage the data was a former accountant who had changed profession specifically to work with children and now found herself again working with numbers. Within the high stakes performativity culture, data production, tracking and mining had became 'the new technical professionalism' (Ball et al 2012, 523).

\section{The Prioritisation of Institutional Performance}

The interviews revealed that the case study sites were firmly located within an hegemony of performativity in which the discourses of school accountability were so dominant that there was little space for alternatives:

'I should be in classrooms supporting colleagues but I spend far too much time looking at assessment data and it is for proving to OFSTED that we are great. I'm an expert at speaking to OFSTED and tell them everything they want to know about data in our school. But actually I would be far more effective if I were in class and the children would benefit more. But I get patted on the head by OFSTED because I really know that data.... The head's job rests on whether the data is good or bad, so this in turn puts masses of pressure all the way down through the school and into the early years'. (Deputy Head teacher, Easthorne Primary school; our emphasis).

This deputy head teacher's professionalism was made up by data-based accountability as she 'attempted to find a balance between the interest of the students and the interest of the school' (Ball and Maguire, 2012, 72). Because the consequences of not producing the 'right' data for Ofsted was severe ${ }^{\mathrm{i}}$, so that the data driven 'regimes of truth' such as 'tracking progress', 'reducing the gap' and 'value added' took precedence over her time. This teacher's enactment of being a data 'expert' replaced 'what is important, with what is measurable' (Nikel and Lowe 2010, 596) so that numerical expertise 'trumped' classroom experience and knowledge. In a further example of how institutional performance for the 'high stakes' Ofsted inspections triumphed over early years pedagogy, one of the Reception teachers at Easthorne wanted the children to play with maths construction equipment but was told that the Head teacher wanted more 'formal maths input because sacrifices had to be made to ensure that the school's outstanding status be maintained.' Here the wealth of research (Broadhead, 
2006; Moyles, 2014) demonstrating the value of play based approaches to learning was 'sacrificed' at the altar of 'outstanding' grading so that the enactment of performance data became an urgent professional necessity within which other versions of the 'good school' became 'unthinkable' (Ball and Maguire, 2012, 135). Similarly, Roberts-Holmes (2015) identified a process of ‘educational triage' (Gillborn and Youdell, 2000) occurring within Reception classes to ensure that the school achieved its required Good Level of Development (GLD) performance despite the fact that this led to a 'systematic neglect' of particular children who were deemed as unlikely to achieve their Good Level of Development at the end of Reception.

\section{Datafication and hierarchies of power}

The Reception teacher above noted that 'unfortunately data is often used by others to direct us and to tell us what to do and the danger is that it's used by others and not for our agenda'. This reception teacher found that the accountability data he collected was recycled back to him as percentage targets steering his pedagogy. Teachers both collected data from children through 'watching' them and at the same time were themselves 'watched' through a comparative performance of the data they collected; they were the 'watched watchers' (Taylor 2014, 11) and despite their reservations about the pedagogical usefulness of this constant data accountability collection, the teachers were compelled to produce and pass it on to senior management and the Local Authority. The current holistic baseline, which measures children's progress against Development Matters in the Autumn term, is sent to the Local Authority (LA) who data mine it and predict where the children could be for their summative Good Levels of Development (GLD) at the end of the Reception year in the summer term. This process of governance through data was made clear by the Local Authority advisor,

\footnotetext{
'Schools currently do a baseline on entry to Year R, and send it to us and we carefully analyse the baseline and do a projected Good Level of Development. Schools use that in-depth analysis of the data as a support and challenge to drive improvements forward. We set a percentage projection but it is a very crude one - so they need to go back and check it and drill right down into it to set challenges for themselves'. (Local Authority Advisor; our emphasis).
}

This percentage prediction was compared with the school's own prediction, with the LA often setting a higher prediction to 'challenge' the school resulting in continuous reflective feedback, self governance and steerage to achieve the necessary data. Similarly, at Westhill Children's Centre tracking data on the children from the age of two was fed to the Local Authority who monitored, recorded and predicted children's attainment levels.

'We record how the children enter when they are 2, so we have a baseline and then throughout the year we do 3 assessments with the children at set points and then compare them with each other to check that they are on track are making progress. You have to show that you have made 'value added' by the time they reach end of Reception. The LA are using that information to predict how 2 year olds are going to do at the end of FS, KS1, and KS2'. (Deputy Manager, Westhill Children's Centre).

Data production, exchange, mining and prediction had become central within the relationship between the LA and the school; in the Local Authority advisor's area this was manifested in the LA 'data packs' sent to all schools in the area. These data packs compared, contrasted and ranked both locally and nationally a wide 
variety of early years assessment data with the intention of 'naming and shaming' to steer whatever pedagogic changes were necessary so that the school improved its competitive ranking (see Tables one and two).

'We 'name and shame' by showing all the school names. Some schools didn't have any children at 'working above the expected level' so you say 'well your statistical neighbour has this \% so how come you haven't?' And they think 'I'd better go back and have another look at that... It does challenge them and that's why we do it. It's accepted and I've not had any adverse comments. It was agreed by the Heads that they wanted that'. (Local Authority Advisor).

Foucault $(1979,181)$ suggests that such hierarchical ranking of students, or in this case schools, 'serves as a reward or punishment' disciplining schools through ranked competitive performances. This leads to 'a highly reductionist' policy and 'a comparative narrative about 'who does better or worse' and thus constructs the need to improve test scores as the only sound basis for undertaking educational reform' (Lingard, Sellar, Savage, $2014,725)$.

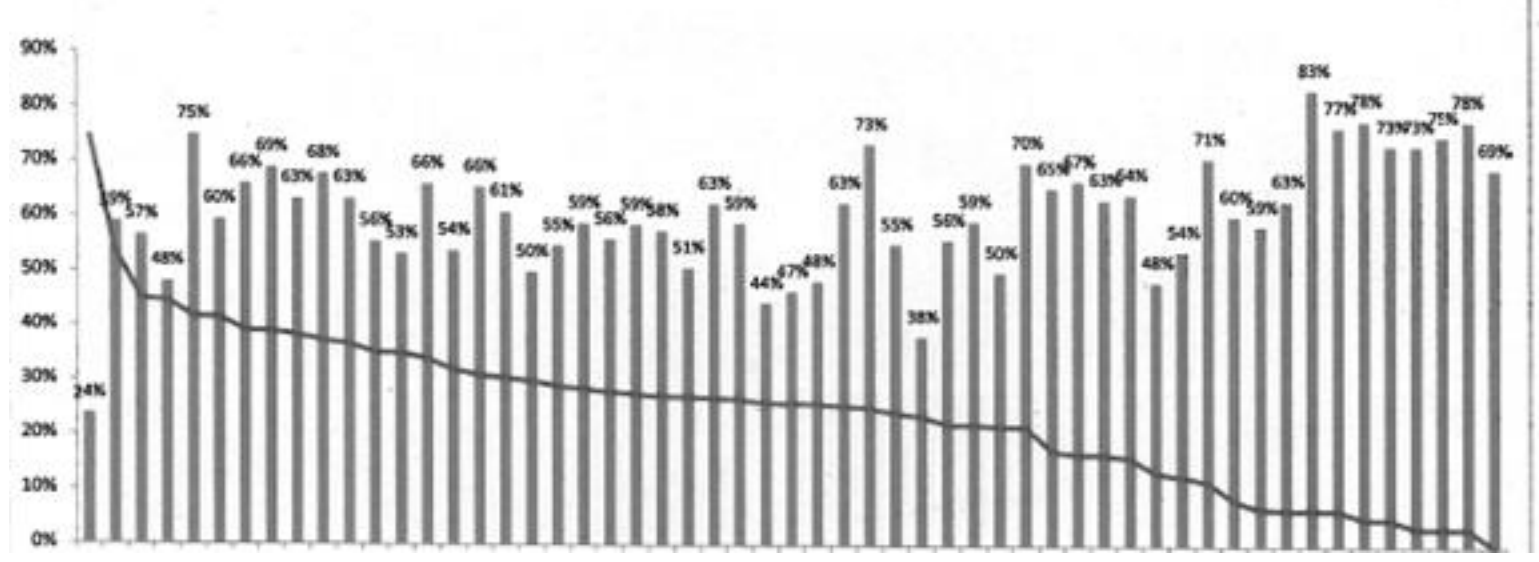

School names

Comparative Graph 1: GLD (Good Level of Development) Percentages plotted against Schools with FSM (Free School Meals) line running across graph.

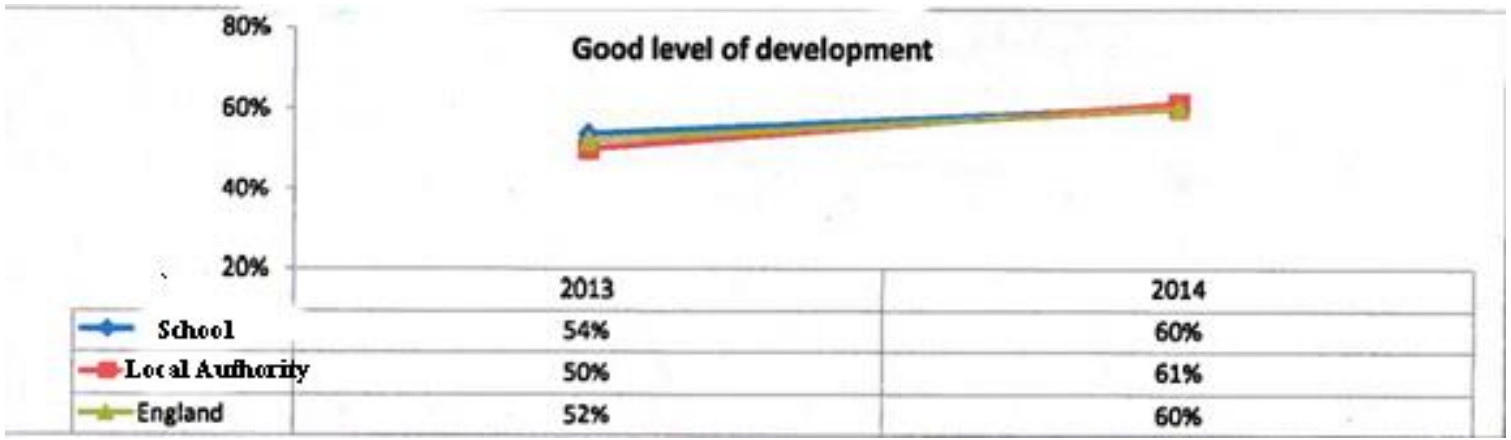


Comparative Graph 2: School, LA and English GLD Percentage Averages $(2013,14)$ averages

This disciplinary process had the effect of getting Reception teachers to 'go back and have another look', such that comparative data $i s$ the process of governing through a 'constant self-evaluation' of performance (Fenwick et al 2014, 5). Collegiality between settings became replaced by competition between 'statistical neighbours' as the Local Authority data packs and the digital data dash boards such as Fisher Family Trust, Ofsted,

RAISEOnline, and various Local Authority Target Trackers rendered the school and its teachers ever more visible subjecting them to greater disciplinary power in the form of moderation, inspection and self-regulation. Accordingly, pedagogical discussion and change was reduced to improving performance data (Lingard, et al, 2014).

Simplistic comparative data sets comparing LA and national data in this manner serves to conceal any local 'irregularities, histories and struggles over the meaning of data' (Ozga, 2011, 87). Foucault notes how 'visibility is a trap' (1979) but argues that it is a trap which we ourselves construct. Accordingly, asked what she thought of the LA data packs, one of the EYFS co-ordinators stated that not only did she like comparing her school locally and nationally but she also wanted to compare her school with European data. This teacher's will to know and the will to perform reinforced the authority of the data packs and amplified their visibility so that 'it feels as if 'we' are permanently in need of information in order to position ourselves and to improve our position' (Simons, 2014, 155). Osgood (2010; 122) similarly noted how early years teachers regulated themselves in such a way that 'power became invisible and therefore impossible to challenge or negotiate'; indeed, this teacher's professional desire for self-governance meant that she wanted more data for even stronger self-governing. This continuous self-governing 360 degree comparative feedback takes aspects of both the panopticon and the synopticon by 'promoting a kind of self-government that includes a staging in the centre and where one submits oneself permanently, voluntary and openly to the gaze of others' (Simons 2014, 167) and can be illustrated as follows: 


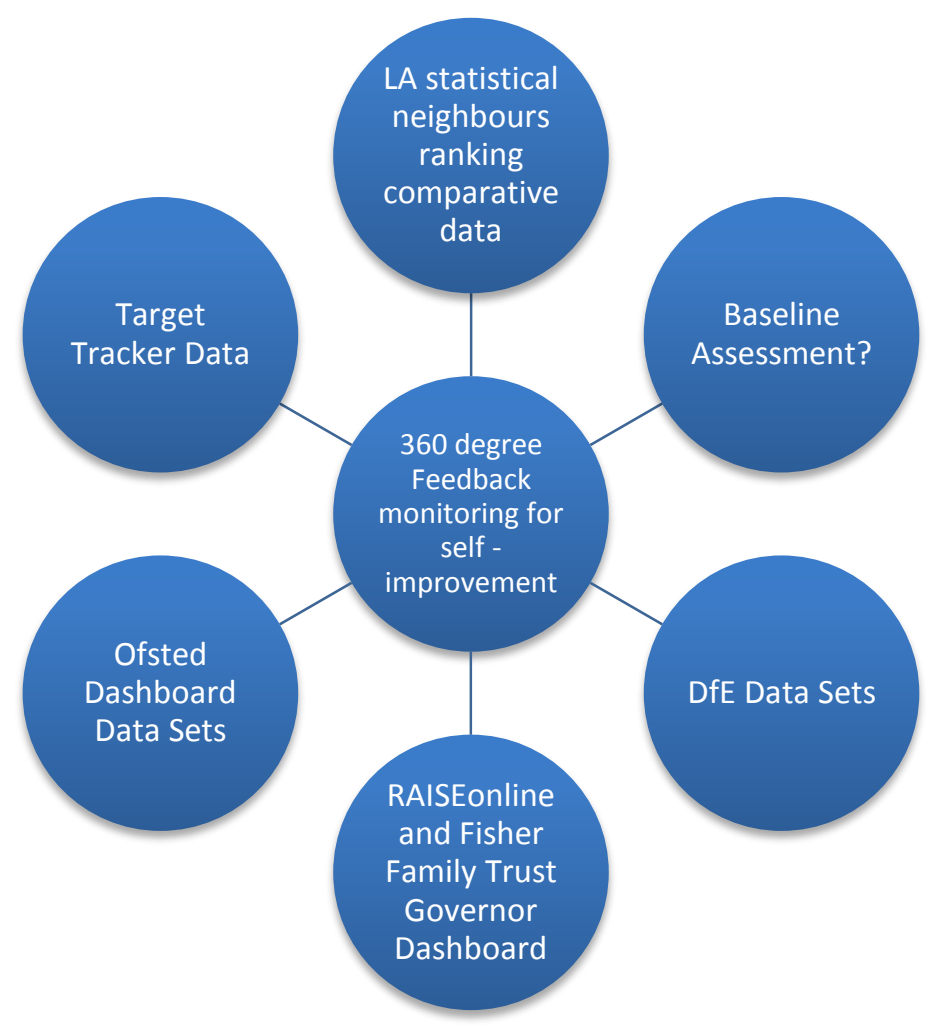

Diagram showing the 360 degree digital comparative feedback .

The multiple data sources above allow early years settings to constantly compare, contrast and to take action to govern themselves and that the Local Authority data packs were experienced as 'indispensable' in this process (Fenwick et al, 2014, 9). Here the collection and distribution of LA data, including naming and shaming where necessary, became 'a powerful steering mechanism' (Simons 2014, 159) which had the effect of keeping the Reception teachers in a constant state of 'competitive self-improvement' (Simons, 2014, 155). This proliferation and replication of governing datasets, the 'isomorphism of measurement' Ball and Junemann $(2012,133)$ meant that the mobile digital post-panopticism evident in these early years sites had become 'cyborgized with muscles so mighty that Bentham or even Foucault could not and would not have imagined them' (Bauman and Lyon 2014, 55) and that Bentham's plan of a 'network of mechanisms that would be everywhere and always alert, running through society without interruption in space or in time' (Foucault, 1977 , 209) had become a reality for these early years teachers.

\section{Conclusion}

We suggest that the three case study sites increasingly operate as 'self-generating hubs of data production and flow' (Lawn, 2013, p. 9) that is used to self-govern their organisation. Within this, the early years are becoming the precarious foundation of the elaborate edifice of tracking progress. Specifically, the early years has become increasingly drawn into the school 'delivery chain' (Ball et al., 2012; 
Moss, 2014) partly enabled by the increased circulation and flow of digital data through which teachers measure performance between the input of the nursery to the end of Primary school and, recently, explicitly through to GCSEs (DfE, 2014).2

Within the case study sites, this research has exemplified how national comparative data sets increasingly govern local early years practice; so that local contextualised professionalism is shifted towards producing objective numerical data for comparison within a highly centralised national system. Williamson (2014a), argues that databases, reinvent teachers and children 'into data that can be measured, compared, assessed and acted upon' and suggests that children become reconfigured as 'miniature centres of calculation' (Williamson, 2014a, p. 12). Similarly Hutchings (2015) found that schools had become 'exam factories' in which children felt reduced to a statistic. Within this there is a sense that young children could become reduced to the school's statistical 'raw materials' that are mined and exploited for their maximum productivity gains.

In the USA over a decade ago, Hatch and Grieschaber (2002, p. 231) warned that young children 'are experiencing anxiety and sometimes failure' because of inappropriate accountability expectations and in a similar critique of the unintended consequences of accountability (TACTYC, 2015) argue that Reception Baseline Assessment testing may label vulnerable children as 'failing' in the first few weeks of their schooling. Such detrimental effects upon young children's well-being was demonstrated by the following nursery teacher's comments:

I am now pushing information into three-year-olds rather than developing meaningful relationships. Even in the nursery I now feel that pressure. If a child doesn't recognize a number or a letter I go “aggghh' and hold my breath. I have to remind myself the child is three and not yet ready for it. (Reception teacher, Easthorne Primary school) 
This nursery teacher struggled as he attempted to find the balance between the discourse

of institutional performance and the needs of a three-year-old child. As the

plethora of comparative datasets grows more complex and increasingly visible on the

web to a widening group of stakeholders, we argue that there is a growing tension

between high stakes school based performativity and young children's appropriate learning needs.

\section{Acknowledgements}

Thanks to all the early years teachers who contributed with their ideas and shared their precious time and experience and who continue to struggle with all the above. Thanks to Professor Peter Moss Also and also for the time and care from the three very helpful anonymous referees.

\section{References}

Ball, S. (2003) The teacher's soul and the terrors of performativity, Journal of Education Policy 18(2), 215228.

Ball, S. and Maguire, M. (2012) How Schools Do Policy Policy Enactments in Secondary Schools (London, Routledge).

Ball, S., M. Maguire, A. Braun, J. Perryman, \& K. Hoskins, (2012) Assessment technologies in schools, 'deliverology' and the 'play of dominations', Research Papers in Education 27 (5), 513-533.

Ball, S. and Junemann, C., (2012) Network Governance and Technology (Bristol, Policy Press).

Ball, S. (2013) (2 ${ }^{\text {nd }}$ Ed) The Education Debate (Bristol, Policy Press)

Ball, S. J. and A. Olmedo (2013) Care of the self, resistance and subjectivity under neoliberal governmentalities, Critical Studies in Education 54(1), 85-96.

Ball, S.J. (2014) Education-and-the-tyranny-of-numbers. Available online at, https,//ioelondonblog.wordpress.com/2014/11/16/education-and-the-tyranny-of-numbers (accessed 6th January 2015).

Bauman, Z. and Lyon, D. (2014) Liquid Surveillance (Cambridge, Policy Press).

Bradbury, A. (2012) "I feel absolutely incompetent", professionalism, policy and early childhood teachers. Contemporary Issues in Early Childhood Education 13(3).

Bradbury, A. (2012) "I feel absolutely incompetent", Professionalism, policy and early childhood teachers Contemporary Issues in Early Childhood 13 (3), 175-186

Bradbury, A. (2013) Understanding Early Years Inequality, policy, assessment and young children's identities (London, Routledge).

Broadhead, P. (2006) Developing an understanding of young children's learning through play, the place of observation, interaction and reflection British Educational Research Journal 32, (2) 191-207

Department for Education (DfE, 2010) The Importance of Teaching, The Schools White Paper 2010. DfE, London. 
Department for Education (DfE, 2011) Statutory Framework for the Early Years Foundation Stage. Available online at, http,//www.education.gov.uk/consultations/index.cfm (accessed July 10, 2013).

Department for Education (DfE, 2013a) Early Years Foundation Stage Handbook 2013. Available at https,//www.gov.uk/government/publications/early-years-foundation-stage-profile-handbook-2013 (accessed September 5, 2013).

Department for Education (DfE, 2014) "Reforming assessment and accountability for primary schools". Available at https,//www.gov.uk/government/uploads/system/uploads/attachment_data/file/297595/Primary_Accountability_ and_Assessment_Consultation_Response.pdf (accessed March 10, 2014).

Dahlberg, G., Moss, P., \& Pence, A. (2007). Beyond quality in early childhood education and care, Languages of evaluation (2nd Ed.). London, Falmer Press

Fenwick. T., Mangez, E., and Ozga.J. (Eds) (2014) Governing Knowledge, Comparison, Knowledge-Based Technologies and Expertise in the Regulation of Education, (World Yearbook of Education 2014) (London, Routledge).

Foucault, M. (1977) Discipline and Punish, The Birth of the Prison (London, Penguin Books).

Gove, M. (2009) A comprehensive programme for state education. Available online at, http,//www.conservatives.com/News/Speeches/2009/11/Michael_Gove_A_comprehensive_programme_for_stat e_education.aspx

Gillborn, D. and D. Youdell (2000) Rationing education, policy, practice, reform and equity. Buckingham, (Oxford, Open University Press).

Hatch, J. \& Grieshaber, S. (2002) Child Observation and Accountability in Early Childhood Education, Perspectives from Australia and the United States, Early Childhood Education Journal 29 (4), 227-231.

Hutchings, M. (2015) The Impact of Accountability Measures on Children and Young People, Emerging Findings. Available Online at, https,//www.teachers.org.uk/node/23627

Jones, L., Osgood, J., Holmes, R. \& MacLure, M. (2014) Eu(rope) (Re)assembling, (Re)casting, and (Re)aligning Lines of De- and Re-territorialisation of Early Childhood International Review of Qualitative Research 7(1) 58-79

Lawn, M. (2013) The Rise of Data in Education Systems, Collection, visualisation and uses. (Symposium Books).

Lingard, B., W. Martino and G. Rezai-Rashti (2013) Testing regimes, accountabilities and education policy, commensurate global and national developments, Journal of Education Policy 28(5), 539-556.

Lingard, B., Sellar, S., \& Savage, G. (2014) Re-articulating social justice as equity in schooling policy, the effects of testing and data infrastructures, British Journal of Sociology of Education, 35 (5), 710-730.

Moss, P. (2014) Transformative Change and Real Utopias in Early Childhood Education, A story of democracy, experimentation and potentiality. (Oxon, Routledge).

Moyles, J. (2015) (4 ${ }^{\text {th }}$ Ed) The Excellence of Play (Open University Press).

Nikel, J. and Lowe, J (2010) Talking of Fabric, A multi-dimensional model of quality in education Compare $40(5), 589-605$.

Osgood, J. (2010) Reconstructing professionalism in ECEC, the case for the 'critically reflective emotional professional', Early Years, An International Research Journal, 30 (2) 119-133.

Osgood, J. (2012) Narratives from the Nursery, negotiating professional identities in early childhood. (London, Routledge) 
Osgood, J. \& Giugni, M. (2015) 'Reconfiguring 'quality', beyond discourses and subjectivities to matter, bodies and becomings in early childhood education’ in G.S.Cannella, M. Salazar Perez, I. Lee. (Eds). Critical Examinations of Quality in Childhood Education and Care, Regulation, Disequalification, and Erasure. (Peter Lang)

Ozga, J. (2009) Governing Education through data in England, from regulation to self-evaluation. Journal of Education Policy 24(2), 149-162.

Ozga, J., Dahler-Larsen, P. Segerholm, C. and Simola, H., (2011) Fabricating Quality in Education, Data and Governance in Europe (London, Routledge).

Perryman, J. (2009) Inspection and the fabrication of professional and performative processes. Journal of Education Policy 24 (5), 611-631.

Roberts-Holmes, G. (2015) The 'datafication' of early years pedagogy, if the teaching is good, the data should be good and if there's bad teaching, there is bad data'." Journal of Education Policy, 30 (3) 302-315.

Roberts-Holmes, G. (2015) High Stakes Assessment, Teachers and Children in Wyse, D. Rogers, S. and Jones, P. (2015) Exploring Education and Childhood, From current certainties to new visions (London, Routledge).

Selwyn, N. (2015a) Data entry, towards the critical study of digital data and education Learning, Media and Technology. Journal of Learning, Media and Technology, 40 (1), 64-82.

Selwyn, N., Henderson, M. and Chao, S. (2015b) Exploring the role of digital data in contemporary schools and schooling — '200,000 lines in an Excel spreadsheet' British Educational Research Journal. Available Online at, DOI, 10.1002/berj.3186

Simons, M (2014) Governing Through Feedback in Fenwick. T., Mangez, E., and Ozga.J. (Eds) (2014) Governing Knowledge, Comparison, Knowledge-Based Technologies and Expertise in the Regulation of Education, (World Yearbook of Education 2014) (London, Routledge).

TACTYC (Association for the Professional Development in Early Years) (2015) Position Statement, Say No to Baseline Assessment http,//tactyc.org.uk/wp-content/uploads/2014/10/TACTYC-Baseline-position-paper-1.pdf

Taylor, E. (2014) Surveillance Schools, Security, Discipline and Control in Contemporary Education (London, Palgrave Macmillan).

UK Government. (2014). Free early education and childcare Available online at, https,//www.gov.uk/freeearly-education\#. (accessed 16 July 2014)

Urban, M. (2015) From 'Closing the Gap' to an Ethics of Affirmation. Reconceptualising the Role of Early Childhood Services in Times of Uncertainty European Journal of Education Available online at, DOI, 10.1111/ejed.12131

Williamson, B. (2014a) Reassembling children as data doppelgangers, How databases are making education machine-readable Powerful Knowledge conference $16^{\text {th }}$ May 2014, University of Bristol.

Williamson (2014b) New Governing Experts in Education - Self-Learning Software, Policy Labs and Transaction Pedagogies in Fenwick. T., Mangez, E., and Ozga.J. (Eds) (2014) Governing Knowledge, Comparison, Knowledge-Based Technologies and Expertise in the Regulation of Education, (World Yearbook of Education 2014) (London, Routledge). 
iSubsequent to this research, the DfE's (2015) Education and Adoption Bill has further increased the disciplinary consequences of 'failure' to collect and produce the 'right' accountability data https,//www.gov.uk/government/news/up-to-1000-failing-schools-to-be-transformed-under-new-measures. 